www.jmscr.igmpublication.org

Index Copernicus Value: 79.54

ISSN (e)-2347-176x ISSN (p) 2455-0450

crossref DOI: https://dx.doi.org/10.18535/jmscr/v7i6.122

\title{
A Comparative Study between Antegrade (Transperitoneal) and Retrograde (Extraperitoneal) Radical Cystectomy Regarding Recovery of Bowel Function
}

\author{
Authors \\ Osama Zaytoun MD ${ }^{1}$, Mostafa Abdelkarim MD², Ahmed El-Abbady ${ }^{3}$, Wael Sameh \\ ${ }^{1}$ Lecturer at Urology Department Alexandria University \\ ${ }^{2}$ Urologist at Abu-Kir Specialized Hospital, Alexandria \\ ${ }^{3,4}$ Professor at Urology Department Alexandria University
}

\begin{abstract}
Purpose: Antegrade transperitoneal radical cystectomy is the standard surgical treatment for muscleinvasive bladder cancer. Another approach was established in 1999 by kulkarni et al. a retrograde extraperitoneal approach including extraperitonealization of the ileal neobladder. This study compares the results of the two procedures focusing on postoperative recovery of bowel function and postoperative ileus. Methods: Forty five patients who underwent radical cystectomy and urinary diversion at urology department of faculty of medicine in Alexandria University from January 2015 to December 2017 were analyzed. Twenty two patients underwent antegrade transperitoneal radical cystectomy. Other twenty three were submitted to the retrograde extraperitoneal technique with extraperitonealization of the neobladder or ileal conduit whenever possible. We compared both techniques regarding postoperative recovery of bowel function and postoperative ileus.

Results: The recovery of intestinal movement including Peristalsis and passage of flatus was significantly earlier in the extraperitoneal approach than after the transperitoneal approach. Regarding to regaining of Peristalsis (mean 15.91 vs. 41.59 hrs; $p=<0.001$ ), according to flatus passage (mean 43.83 vs. $73.73 \mathrm{hrs;}$ $p=0.001$ ), respectively.

Conclusions: The retrograde extraperitoneal technique with extraperitonealization of the ileal neobladder or ileal conduit yields significant early recovery of bowel function than the antegrade transperitoneal surgical approach.
\end{abstract}

\section{Introduction}

Bladder cancer (BC) is one of the most common cancer worldwide with a strong male predominance. $^{(1)}$ Both computed tomography (CT) and magnetic resonance imaging (MRI) are used to detect BC. ${ }^{(2)}$

$\mathrm{BC}$ remains a surgical disease; optimal outcomes for both noninvasive and invasive tumors require good surgical technique. Radical cystectomy (RC) is performed to minimize local recurrence and development of metastatic disease. Toward these goals, negative margins must be achieved, and an appropriate lymph node dissection (LND) must be performed at the time of cystectomy. ${ }^{(3)}$ patients with non muscle invasive bladder tumor (NMIBT) at highest risk of progression should also be considered for $\mathrm{RC}^{(4)}$ 
Ileus was defined as postoperative nausea or vomiting associated with abdominal distension requiring cessation of oral intake and intravenous fluid support and/or nasogastric tube placement, or the intolerance of oral intake by postoperative day 5 resulting in patient fasting with or without nasogastric tube placement or antiemetic medication administration. ${ }^{(5)}$

The most commonly used surgical technique is the antegrade descending transperitoneal approach. ${ }^{(6)}$ The peritoneal cavity is entered early in the procedure, leading to unnecessary bowel exposure to the atmosphere. Mobilization of the bowel often disturbs the operative field during cystectomy. Packing the bowels into the upper abdomen may cause mechanical damage. ${ }^{(7)}$ Late opening of the peritoneum the extraperitoneal technique notably involves opening the peritoneal cavity at the end of cystectomy. ${ }^{(5)}$

Extraperitonealization of the ileal neobladder or ileal conduit separates the uretero-ileal anastomosis in front of the contaminated small bowel anastomosis and enables local management of complications. The short peritoneal opening and the separation of local healing processes minimize the effect on the intestinal tract and thus reduce the postoperative colonic motility disorder. Another explanation for the lower incidence of colonic motility disorders may be leakage of urine from the not yet fully healed neobladder. In contrast, extraperitonealization of the neobladder eliminates the effect on the intestinal compartment. $^{(5)}$

In extraperitoneal retrograde approach ligation of dorsal vein complex decrease blood loss and allow good visualization of anatomy. ${ }^{(8)}$ Division of the urethra early in the retrograde method leads to correct identification of the rectovesical plane, since this dissection may be done under direct vision in contrast to blind and blunt finger dissection in the conventional method. ${ }^{(8)}$ Developing this plane after incising the cul-de-sac peritoneum is considered critical in antegrade $\mathrm{RC}$, and the most common error at this point is the tendency to establish this plane of dissection too far anterior due to fear of injuring the rectum. ${ }^{(9)}$ Which leads into a wrong plane between the posterior bladder wall and seminal vesicles. ${ }^{(9)}$

The postoperative bowel motility disorder is the most frequent complication of the transperitoneal technique, occurring in up to $35 \%$ of the patients. ${ }^{(10)}$ Avoiding this complication may be accomplished by late opening and re-closure of the peritoneal cavity; it seemed useful to develop the extraperitoneal approach during $\mathrm{RC}$ and pelvic LND, where the peritoneum is only briefly opened for a short distance to construct a urinary conduit. (11)

\section{Patients and Methods}

A total of 45 patients were operated randomly and data collected prospectively at urology department of faculty of medicine in Alexandria University. This study has been done between January 2015 until December 2017 and has been approved by the ethical committee. All persons gave their informed consent prior to their inclusion in the study. 22 patients underwent the classic transperitoneal RC with urinary diversion. The remaining 23 were included in the extraperitoneal technique with extraperitonealization of the neobladder or ileal conduit.

Pre-operatively, all patients underwent bowel preparation one day before surgery. They also had a 12-h solid food fast and liquid fast prior to the intervention. Anesthesia was supplemented by epidural anesthesia.

The extraperitoneal surgical technique was performed using the approach described by kulkarni et $\mathrm{al}^{(8)}$. The transperitoneal surgical technique was performed in the usual manner as described by Lieber ${ }^{(9)}$.

Postoperatively, all patients in both groups were monitored in ICU on the first postoperative day. All patient received analgesia at regular base for the same duration. All patient received potassium chloride supplementation for the same duration to keep serum potassium in normal range to avoid hypokalemia. They were then routinely monitored on our urological ward and treated according to 
our standardized cystectomy clinical care pathways. This involved removal of the gastric tube one day after surgery, and standard mobilization and standard nutritional buildup.

Monitoring of peristalsis recurrence using stethoscope and flatus passage at regular base by the same surgeon postoperatively at $8-12 \mathrm{hrs}, 12-$ 24 hrs, 24-36 hrs, 36-48 hrs then daily. Once flatus passed, patients received an increase in liquid food. A gradual buildup with solid food components and full mobilization were initiated on the subsequent postoperative day.

\section{Results}

This study was carried out on 45 patients who underwent RC with standard bilateral PLND divided into 2 groups:

Group I: patients who were operated through antegrade technique (22 patients).

Group II: patients who were operated through retrograde technique (23 patients).

As shown in (table 1-5), there were no statistically significant difference between two groups as regard age ,sex, histopathological characterisctics of preoperative TURBT, duration of cystectomy and lymph node dissection, staging of tumor and number of lymph node dissection.

As shown in (table 3), Regarding to type of diversion in group I, 20 patients $(90.9 \%)$ had ileal conduit as urinary diversion and 2 patients $(9.1 \%)$ had ureterocutanous type of diversion and in group II, 16 patients had ileal conduit $(69.6 \%)$ as type of diversion, 1 patient had permanent bilateral PCN (4.3\%) and 6 patients had orthotopic neobladder bladder $(26.1 \%)$ which demonstrate statistically significant difference between both groups regarding type of diversion

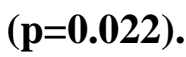

As shown in (table 6), there was statistically significant difference between both groups regarding intra-operative estimated blood loss $(p=0.036)$. In group I the mean estimated blood loss was $1480 \mathrm{ml}$ versus $1000 \mathrm{ml}$ in group II.

As shown in (table 7), the regaining of bowel function including The regaining of peristalsis in antegrade group ranged from $12-120$ hrs post operative with mean 41.59 hrs. in retrograde group it ranged from 8-36 hrs postoperative with mean $15.91 \mathrm{hrs}$ which was statistically significant $(\mathbf{p}=<\mathbf{0 . 0 0 1})$. Regarding flatus passage in antegrade group it ranged from 24-144 hrs postoperative with mean 73.73 hrs while in retrograde group it ranged from $24-120 \mathrm{hrs}$ with mean $43.83 \mathrm{hrs}$ which is statistically significant $(\mathbf{p}=\mathbf{0 . 0 0 1})$. There was no statistically significant difference between both groups regarding stool passage $(\mathrm{p}=0.062)$ and also, postoperative ileus there was no statistically significant difference $(\mathrm{p}=0.608)$.

Serum electrolytes (sodium and potassium) were in normal range because of every patient had regular supplementation.

Table (1): Comparison between the two studied groups according to demographic data

\begin{tabular}{|c|c|c|c|c|c|}
\hline \multirow{2}{*}{ Demographic data } & \multicolumn{2}{|c|}{ Group I } & \multicolumn{2}{|c|}{ Group II } & \multirow[b]{2}{*}{$\mathbf{p}$} \\
\hline & No. & $\%$ & No. & $\%$ & \\
\hline \multicolumn{6}{|l|}{ Sex } \\
\hline Male & 19 & 86.4 & 22 & 95.7 & \multirow[b]{2}{*}{0.346} \\
\hline Female & 3 & 13.6 & 1 & 4.3 & \\
\hline Age (years) & \multirow{4}{*}{\multicolumn{2}{|c|}{$\begin{array}{c}50.0-78.0 \\
63.27 \pm 7.13 \\
63.0\end{array}$}} & \multirow{4}{*}{\multicolumn{2}{|c|}{$\begin{array}{c}40.0-77.0 \\
62.57 \pm 8.60 \\
63.0\end{array}$}} & \multirow{4}{*}{0.766} \\
\hline Min. - Max. & & & & & \\
\hline Mean \pm SD. & & & & & \\
\hline Median & & & & & \\
\hline
\end{tabular}


Table (2): Comparison between the two studied groups according to histopathology of TURBT

\begin{tabular}{|lc|c|c|c|c|c|}
\hline Histopathology & of & \multicolumn{2}{|c|}{ Group I } & \multicolumn{2}{c|}{ Group II } & \multirow{2}{*}{ p } \\
\cline { 2 - 5 } TURBT & No. & \% & No. & \% & \\
\hline Grade & & & & & \\
$\quad$ Low & 0 & 0.0 & 1 & 4.3 & \multirow{2}{*}{1.000} \\
High & 22 & 100.0 & 22 & 95.7 & \\
\hline Type & & & & & \\
TCC & 20 & 90.9 & 23 & 100.0 & \\
Squamous & 2 & 9.1 & 0 & 0.0 & 0.233 \\
Adeno & 0 & 0.0 & 0 & 0.0 & \\
\hline
\end{tabular}

Table (3): Comparison between the two studied groups according to duration of cystectomy with lymph node dissection and type of diversion

\begin{tabular}{|l|c|c|c|c|c|}
\hline \multirow{2}{*}{} & \multicolumn{2}{|c|}{ Group I } & \multicolumn{2}{c|}{ Group II } & \multirow{2}{*}{ p } \\
\cline { 2 - 4 } & No. & \% & No. & \% & \\
\hline Total Time of operation (min) & \multicolumn{2}{|c|}{$180.0-390.0$} & \multicolumn{2}{|c|}{$240.0-360.0$} & \\
Min. - Max. & \multicolumn{2}{|c|}{$278.64 \pm 63.74$} & \multicolumn{2}{|c|}{$294.43 \pm 39.66$} & 0.327 \\
Mean + SD. & \multicolumn{2}{|c|}{260.0} & \multicolumn{2}{|c|}{300.0} & \\
Median & 0 & 0.0 & 1 & 4.3 & \multirow{2}{*}{1.000} \\
Type of diversion & 20 & 90.9 & 16 & 69.6 & 0.135 \\
Bil pcn & 2 & 9.1 & 0 & 0.0 & 0.233 \\
Ileal conduit & 0 & 0.0 & 6 & 26.1 & $\mathbf{0 . 0 2 2}^{*}$ \\
Ureterocutanous &
\end{tabular}

Table (4): Comparison between the two studied groups according to TNM staging

\begin{tabular}{|c|c|c|c|c|c|}
\hline \multirow{2}{*}{ Histopathology stage } & \multicolumn{2}{|c|}{ Group I } & \multicolumn{2}{|c|}{ Group II } & \multirow{2}{*}{${ }^{\mathrm{MC}} \mathbf{p}$} \\
\hline & No. & $\%$ & No. & $\%$ & \\
\hline Stage I & 0 & 0.0 & 1 & 4.3 & \multirow{4}{*}{0.333} \\
\hline Stage II & 8 & 36.4 & 13 & 56.5 & \\
\hline Stage III & 7 & 31.8 & 4 & 17.4 & \\
\hline Stage IV & 7 & 31.8 & 5 & 21.7 & \\
\hline
\end{tabular}

Table (5): Number of dissected LN in both groups

\begin{tabular}{|c|c|c|c|c|c|}
\hline & \multicolumn{2}{|c|}{ Group I } & \multicolumn{2}{|c|}{ Group II } & \multirow{2}{*}{$\mathbf{P}$} \\
\hline & No. & $\%$ & No. & $\%$ & \\
\hline $\begin{array}{l}\text { No. of LNs } \\
\text { Min. - Max. } \\
\text { Mean } \pm \text { SD. } \\
\text { Median }\end{array}$ & \multicolumn{2}{|c|}{$\begin{array}{c}2.0-14.0 \\
7.86 \pm 3.66 \\
8.5\end{array}$} & \multicolumn{2}{|c|}{$\begin{array}{c}2.0-36.0 \\
11.39 \pm 6.87 \\
10\end{array}$} & 0.070 \\
\hline
\end{tabular}

Table (6): Comparison between the two studied groups according to estimated blood loss

\begin{tabular}{|c|c|c|c|}
\hline & Group I & Group II & p \\
\hline Blood loss (ml) & & & \\
Min. - Max. & $710-3000$ & $350-2500$ & \\
Mean \pm SD. & $1480 \pm 709.1$ & $1000 \pm 531.4$ & $\mathbf{0 . 0 3 6}$ \\
Median & 1375.0 & 1000 & \\
\hline
\end{tabular}


Table (7): Comparison between the two studied groups according to peristalsis, flatus, stool passage and post operative ileus.

\begin{tabular}{|l|c|c|c|}
\hline & Group I & Group II & P \\
\hline Peristalsis (hrs.) & & & \\
Min. - Max. & $12.0-120.0$ & $8.0-36.0$ & \\
Mean \pm SD. & $41.59 \pm 24.22$ & $15.91 \pm 9.19$ & $<\mathbf{0 . 0 0 1}^{*}$ \\
Median & 36.0 & 12.0 & \\
\hline Flatus (hrs.) & & & \\
Min. - Max. & $24.0-144.0$ & $24.0-120.0$ & \\
Mean \pm SD. & $73.73 \pm 31.47$ & $43.83 \pm 22.70$ & $\mathbf{0 . 0 0 1}^{*}$ \\
Median & 72.0 & 36.0 & \\
\hline Stool (hrs.) & & & \\
Min. - Max. & $48.0-168.0$ & $48.0-240.0$ & \\
Mean \pm SD. & $108.27 \pm 33.35$ & $92.61 \pm 42.61$ & 0.062 \\
Median & 120.0 & 96.0 & \\
\hline Postoperative ileus (\%) & $9.1 \%$ & $4.3 \%$ & 0.608 \\
\hline
\end{tabular}

\section{Discussion}

RC with pelvic LND is the standard surgical treatment for muscle invasive bladder cancer. There are two known approaches for RC; transperitoneal antegrade approach and extraperitoneal retrograde approach. The aim of the current study was to compare between both approaches. The descending transperitoneal approach is the surgical technique most commonly performed. ${ }^{(6)}$ \{Hautmann, $2003 \quad \# 1$; Jentzmik, 2010 \#22 \}

Generally, major abdominal surgery including RC is followed by a delayed return of bowel function attributable to postoperative ileus.$^{(12,13)}$ Factors affecting postoperative ileus after RC and urinary diversion include mechanical bowel preparation and fasting which leave their consequences on postoperative bowel motility ${ }^{(12,13)}$, the utilized approach transperitoneal versus extraperitoneal. ${ }^{(14)}$ Hypovolemia and blood loss are also associated with increased risk of postoperative ileus. ${ }^{(12,13)}$

Nasogastric tubing may be of help to obtain bowel decompression. It is maintained traditionally in the postoperative period, with the purpose of preventing complications such as nausea and vomiting, stomach content aspiration, anastomotic intestinal leakage, and wound dehiscence. ${ }^{(15)}$ The postoperative colonic motility disorder is the most frequent complication of the transperitoneal technique, occurring in up to $35 \%$ in the published series. ${ }^{(10)}$ In our study we encountered this complication in $9.1 \%$ of transperitoneal approach of RC.

One technique to avoid this complication is late opening and re-closure of the peritoneal cavity whenever possible which seemed useful in development of the extraperitoneal approach during RC with pelvic LND, where the peritoneum is only briefly opened for a short distance to construct a urinary conduit. ${ }^{(11)}$

One of the most frequent surgical complications in the antegrade transperitoneal group of this study was delayed intestinal movement (peristalsis) ( $p=$ $<0.001$ ) and passage of flatus which is significantly delayed when compared to retrograde extraperitoneal group $(\mathrm{p}=0.001)$. Rearding postoperative ileus, which developed in (9.1\%) of patients in transperitoneal antegrade group. In contrast, this complication occurred in only one patient $(4.3 \%)$ of the extraperitoneal retrograde group and was thus statistically insignificant reduction. These results coincide with those of various study groups that also demonstrated a reduction of colonic motility disorders after reperitonealization of the intestinal tract. ${ }^{(11)}$ In one study; passage of flatus was noted earlier in patients had re-adaptation of peritoneum after RC and extended LND and reached statistical significance on postoperative day $3 .^{(16)}$

We believe that the reduction of postoperative paralytic ileus found in the retrograde group 
appears to be largely attributable to the surgical procedure itself.

Although there was no statistically significant difference between both groups in our study regarding postoperative ileus, however there was a trend towards more postoperative ileus in the antegrade transperitoneal approach. The difference between both groups may be better elucidated with a future study which has more number of patients in both groups. Additionally; we believe that postoperative ileus is dependent on multiple factors which may benefit from future multivariate analysis.

The retrograde technique notably involves opening of the peritoneal cavity at the end of cystectomy. In case of peritoneal infiltration or intra-abdominal metastasis in preoperative imaging, we usually apply the extraperitoneal approach for cystectomy and then open the peritoneal cavity secondary for access to the peritoneal lesions and for construction of incontinent diversion. In case of a space problem, the infraumbilical incision is then easily extended. ${ }^{(5)}$

This study had some limitations. First; this is a prospective study over short period (20152017).second, all cases operated by multiple surgeons with different experiences about 4 surgeons. Third, this study didn't care about previous co-morbidities that may affect the result and complications. Lastly, Small number of cases included in study.

\section{Conclusions}

The retrograde extraperitoneal technique with extraperitonealization of the ileal neobladder or ileal conduit yields significant early recovery of bowel function than the antegrade transperitoneal surgical approach

\section{References}

1. Ferlay J, Soerjomataram I, Ervik M, Dikshit R, Eser S, Mathers $\mathrm{C}$, et al. GLOBOCAN 2012 v1. 0, Cancer Incidence and Mortality Worldwide: IARC
CancerBase No. 11 [Internet]. 2013; Lyon, France: International Agency for Research on Cancer. globocan iarc fr/Default aspx 2014.

2. Rajesh A, Sokhi H, Fung R, Mulcahy K, Bankart M. Bladder cancer: evaluation of staging accuracy using dynamic MRI. Clinical radiology 2011;66(12):1140-5.

3. Stein JP, Quek ML, Skinner DG. Lymphadenectomy for invasive bladder cancer. II. technical aspects and prognostic factors. BJU international 2006;97(2):2327.

4. Babjuk M, Oosterlinck W, Sylvester R, Kaasinen E, Böhle A, Palou-Redorta J. EAU guidelines on non-muscle-invasive urothelial carcinoma of the bladder. European urology 2008;54(2):303-14.

5. Jentzmik F, Schostak M, Stephan C, Baumunk D, Lingnau A, Weikert S, et al. Extraperitoneal radical cystectomy with extraperitonealization of the ileal neobladder: a comparison to the transperitoneal technique. World journal of urology 2010;28(4):457-63.

6. Hautmann RE, Gschwend JE, de Petriconi RC, Kron M, Volkmer BG. Cystectomy for transitional cell carcinoma of the bladder: results of a surgery only series in the neobladder era. The Journal of urology 2006;176(2):486-92.

7. Novara G, De Marco V, Aragona M, Boscolo-Berto R, Cavalleri S, Artibani W, et al. Complications and mortality after radical cystectomy for bladder transitional cell cancer. The Journal of urology 2009;182(3):914-21.

8. Kulkarni JN, Gulla RI, Tongaonkar HB, Kashyapi BD, Rajyaguru KB. Radical cystoprostatectomy: an extraperitoneal retrograde approach. The Journal of urology 1999;161(2):545-8.

9. Lieber M, Utz D. Open bladder surgery. Campbell's urology, 5th ed Philadelphia: Saunders 1986:2640-1. 
10. Maffezzini M, Campodonico F, Canepa G, Gerbi G, Parodi D. Current perioperative management of radical cystectomy with intestinal urinary reconstruction for muscle-invasive bladder cancer and reduction of the incidence of postoperative ileus. Surgical oncology 2008;17(1):41-8.

11. Serel TA, Perk H, Koşar A, Soyupek S. Antegrade extraperitoneal approach to radical cystectomy and ileal neobladder. International journal of urology 2003;10(1):25-8.

12. Shafii M, Murphy D, Donovan M, Hickey D. Is mechanical bowel preparation necessary in patients undergoing cystectomy and urinary diversion? BJU international 2002;89(9):879-81.

13. Ram E, Sherman Y, Weil R, Vishne T, Kravarusic D, Dreznik Z. Is mechanical bowel preparation mandatory for elective colon surgery?: A prospective randomized study. Archives of Surgery 2005;140(3): 285-8.
14. Cannon WB, Murphy FT. IV. The movements of the stomach and intestines in some surgical conditions. Annals of surgery 1906;43(4):512.

15. Park HK, Kwak C, Byun SS, Lee E, Lee SE. Early removal of nasogastric tube after cystectomy with urinary diversion: Does postoperative ileus risk increase? Urology 2005;65(5):905-8.

16. Roth B, Birkhäuser FD, Zehnder $P$, Burkhard FC, Thalmann GN, Studer UE. Readaptation of the peritoneum following extended pelvic lymphadenectomy and cystectomy has a significant beneficial impact on early postoperative recovery and complications: results of a prospective randomized trial. European urology 2011;59(2):204-10. 